JHRS, Vol. 2, 2020

DOI: $10.34002 / \mathrm{jhrs} . \mathrm{v} 2 \mathrm{i} 0.20$

\title{
Economic and Environmental Costs and Benefits of Paper Mulberry: A Case Study of Islamabad-Pakistan
}

\author{
Syed Umar Hayat Shah ${ }^{1}$, Anwar Hussain ${ }^{23}$ \\ ${ }^{1}$ Pakistan Institute of Development Economics (PIDE), Pakistan \\ ${ }^{2}$ University of Swat, Pakistan \\ ${ }^{3}$ Corresponding author, anwar@uswat.edu.pk
}

Received: December 30, 2018; Accepted: April 26, 2019

\begin{abstract}
Plants and trees make our cities more attractive and provide many ecosystem services but some of these also cost society in the form pollen allergy. According to an estimates 60-70 percent of the trees in Islamabad are of Paper mulberry. Thirty Percent people are effected each year from pollen allergy in Islamabad. This study evaluated age and gender wise effects of Pollen Allergy on health followed by proposing options for the alternatives of Paper Mulberry. The economic and environmental costs and benefits of Paper mulberry and its alternative plants were also quantified. The annual benefits and costs of Paper Mulberry and its alternative plants were estimated through "The National Tree Benefits Calculator". Descriptive statistics along with expert opinion method was used for the analysis of the data. The pollen allergy affect children more as compared to other age groups and females more as compared to male. Urban respondents were effected more by pollen allergy as compared to rural respondents. Most of the respondents were found effected in the month of March. The average monthly health expenditures of the respondents from pollen were Rs. 879. Pine Rexburg and Kachnar are viable alternatives for Paper Mulberry from both economic and environmental viewpoints. Based on the findings it is concluded that Pine Rexburg and Kachnar are the best alternative for Paper Mulberry in Islamabad. The Capital Development Authority should replace Pine Rexburg and Kachnar with Paper Mulberry in the city. Besides, Government should arrange awareness program especially in the pollen month (March) and should provide free of cost treatment and preventives for the pollen patients.
\end{abstract}

Keywords: paper mulberry, economic costs, environmental costs, pollen allergy, costs and benefit analysis

Plants and trees make our cities more attractive and provide many ecosystem services but some of these also cost society. Paper mulberry is one of the plants which can be used for many productive purposes (Kandylis, Hadjigeorgiou, \& Harizanis, 2009; Seo \& Kim, 2011; Singh \& Makkar, 2002) but it also has a serious health hazards in the form pollen allergy (D'amato et al., 1998; Munoz et al., 1995; White \& Bernstein, 2003). Pollen allergy is a serious risk for asthma patients and people suffering from lung diseases, as the allergy gets transmitted through air (D'amato et al., 2007). The mulberry tree is found throughout the world, including Asia, Eastern and
Midwestern US, and Southern Europe. According to the World allergy organization, about $10-30 \%$ of the global population is afflicted by allergic rhinitis (or hay fever) and 300 million people worldwide affected by asthma (World Allergy Organization, 2011).

In Islamabad, paper mulberry trees are the leading cause of pollen allergy. According to an estimates 60-70 percent of the trees in Islamabad are of Paper mulberry (Rashid, Abbas, \& Rehman, 2014). Most of the people who suffer from severe allergic symptoms, like asthma attack, are sensitive to the pollen of paper mulberry (Rashid et al., 2014). In Islamabad, the pollen 
count goes as high as 55000 per $\mathrm{m}^{3}$ causing severe problems for residents. Thirty Percent (30\%) people are affected each year from pollen allergy in Islamabad (Pakistan Meterological Department, 2012). The paper mulberry tree has been the focus of attention ever since pollen allergy was first recognized as a threat to human health in Islamabad.

In Pakistan, the National Institute of Health is the major institution from which 2.8 million allergy patients have been benefited in the last 29 years. The other units in the government/private hospitals in the country also cure allergy patients but these institutions do not have sufficient medical facilities. In these hospitals the rush can be seen in the pollen allergy months (National Institute of Health, 2014). Generally, significant share of the households' budget goes in medical treatment and particularly the pollen allergy treatment further put pressure on their budget. With this motivation, present study estimated the economic and environmental costs of paper Mulberry and also its age and gender wise effects in Islamabad. Besides, alternatives for the paper Mulberry trees have been proposed. More specifically, the study aims: (1) To evaluate age and gender wise effects of Pollen Allergy on health; (2) To seek options which can be used as alternative for Paper Mulberry; and (3) To analyze the economic and environmental costs and benefits of Paper mulberry and its alternative plants.

\section{Materials and Methods}

The study was conducted in Islamabad and is mainly based on primary data. However, in some cases, secondary data obtained from Pakistan Meteorological Department, Islamabad was also used. In this study opinion of some experts was also taken.

The estimated population of Islamabad is around 2.0 million where $30 \%$ people are affected each year from pollen allergy in Islamabad (Pakistan Meterological Department, 2012). Therefore, considering a population of 60000 of Islamabad ( $30 \%$ of 2 million), confidence level as $95 \%$ and confidence interval as 5.55, the appropriate sample size is 310 respondents. The sample size has been derived using the sample size calculator available at: http:// www.surveysystem.com/sscalc.htm.

The relevant information about the family of the respondents were taken through questionnaire (see Supplementary Data). The respondents were taken randomly from the patients visited the NIH and both rural and urban areas of the city.

The study selected the respondents through random sampling technique. The age and genderwise effects were evaluated using frequencies/ descriptive statistics. The information were taken from the respondents and their families.

For assessing the options (alternative) for Paper Mulberry, experts from Pakistan Agriculture Research Council (PARC), Agro-economists and Doctors, were consulted. They were asked about the month of planation of different plants, the required water level per tree, soil and climate for plant, maturity age of the plant, pollen generation, the Diameter at Breast Height (DBH) maximum and minimum of trees and age of the plant.

The economic and environmental costs and benefits of paper mulberry and its alternative plants were also estimated. The annual benefits of a tree were calculated by the following equations.

$$
B=E+A+C+H
$$

Where: per year

$\mathbf{B}=$ Benefit of a tree in Dollars per year.

$\mathbf{E}=$ Energy (kilowatt/per hour) savings $\$$

improvement \$ per year

$\mathbf{C}=$ Carbon dioxide (per metric ton of corban) reductions $\$$ per year

$\mathbf{H}=$ Storm water (milligram / liter) runoff reductions $\$$ per year. The drops of rain on the leaf of tree which absorbs by the tree through the root and leaf, to protect soil from erosion and clean the water, is called storm water.

To convert $\mathrm{E}, \mathrm{A}, \mathrm{C}$ and $\mathrm{H}$ into monetary term, "The National Tree Benefits Calculator was used."

To estimate the cost of Paper Mulberry and its alternative plants, the following equation was used.

$$
C=T+P / R+W
$$

Where:

$\mathbf{C}=$ Total Cost, Dollar per year.

$\mathbf{T}=$ Initial purchase cost Dollar per year.

$\mathbf{P}=$ Average annual tree pruning cost Dollar per year.

$\mathbf{R}=$ Annual tree and stump removal and disposal cost Dollar per year.

$\mathbf{W}=$ Annual watering and irrigation cost Dollar per year. 
Initial purchase cost $(\mathrm{T})$ was obtained from the different Nursery farms. Removal cost (S) and Pruning Cost $(\mathrm{P})$ revolves around the labor costs and is directly related to the lifespan of the trees. Removal occurs at the end of a tree's life trees or when the tree becomes unmanageable or diseased.

For estimating the watering cost, agricultural scientists and CDA Gardner were consulted.

\section{Results and Discussion}

The effectees of pollen allergy among different age groups are given in table 1. The effectees of pollen allergy is higher in the age group of (1-15) years which is 40.6 percent of the total effecties. The frequency in the age group $16-25$ is low as compared to other age groups. The

Table 1: Age wise pollen allergy effectee.

\begin{tabular}{cc}
\hline Age Group (years) & Percentage (\%) \\
\hline $1-15$ & 40.6 \\
$16-25$ & 9.4 \\
$26-40$ & 27.7 \\
$41+$ & 22.3 \\
\hline
\end{tabular}

Source: Field survey

pollen allergy affect the children more as compared to other age groups. The reason is that children may have low resistance as against other age groups. The Asthma and Allergy Foundation of America also found that Allergies affect as many as 30 percent of adults and 40 percent of children (Asthma and Allergy Foundation of America, 2017). The gender wise effectees of the pollen allergy are given in table 2 which shows that

Table 2: Gender wise effects of pollen allergy affectees.

\begin{tabular}{cc}
\hline Gender & Percentage \\
\hline Male & 44.80 \\
Female & 55.20 \\
\hline Total & 100.00
\end{tabular}

Source: Field survey females are more affected by pollen as compared to male in the sample. Females are more affected by pollen as compared to male due to low resistance. These findings are also in line with the findings of Bennett et al (Bennett, Qazilbash, \& Qazilbash, 1997). However, the gender wise effectees of pollen allergy can be assessed more accurately by extending the sample size.

According to table 3 the effectees of pollen allergy are considerably higher in urban respondents as compared to the rural respondents of Islamabad. In the sample $61 \%$ of the

Table 3: Effectees of pollen from urban and rural area.

\begin{tabular}{cc}
\hline Area of Resident & Percentage \\
\hline Urban & 61 \\
Rural & 39 \\
\hline Total & 100 \\
\hline
\end{tabular}

Source: Field survey

respondents were effected by pollen allergy who were living in the urban areas. The issue of pollen allergy is more severe in urban respondents as against rural respondents. Although these findings are against the findings of Bosch-Cano (Bosch-Cano et al., 2011) and this may be due to the fact that many people come to Islamabad for jobs/residence who have more chances of being affected.

It is clear from table 4 that the pollen symptoms are more in the month of March as compared to other months. In the month of March the number of effectees is maximum.

On the other hand, the total pollen count also increases in the month of March (Table 5). Most of the respondents are affected in the month of March as compared to other months. This is due to the fact the total pollen count is highest in the month of March as represented by the official statistics of Meteorological Department in Islamabad. Furthermore, these findings are also in line with the findings of Haroon et al. (Haroon \& Rasul, 2008), Ghufran et al. (Ghufran, Hamid, Ali, \& Ali, 2013) and D'amato et al. (D'amato et al., 2007). Paper mulberry pollen is the most plentiful pollen type present in the atmosphere of Islamabad. Its peak values start from mid-March and ends in mid-April. 
JHRS, Vol. 2, 2020

Table 4: Percentage of pollen effectees feel different symptom in various months.

\begin{tabular}{lcccccccc}
\hline \multicolumn{1}{c}{ Symptoms } & \multicolumn{7}{c}{ Percent Cases in the Month } \\
& Jan & Feb & Mar & Apr & May & Jun & Jul & Aug \\
\hline Runny nose & 2.6 & 9.4 & 27.7 & 11 & 0.3 & 0 & 0 & 3.2 \\
Itchy nose & 4.2 & 6.5 & 23.2 & 8.4 & 2.9 & 0 & 0 & 0 \\
Wheezing coughing & 5.8 & 6.8 & 18.7 & 5.5 & 0.3 & 0 & 0 & 0 \\
W.C with exercise & 0.6 & 1.3 & 3.5 & 1 & 0 & 0 & 0 & 0 \\
Skin problems & 0.3 & 3.5 & 21.3 & 8.7 & 4.8 & 0 & 1 & 1.6 \\
\hline
\end{tabular}

Source: Field survey

Table 5: Average monthly wise pollen count in Islamabad from 2004 to 2014.

\begin{tabular}{lccccccccccc}
\hline Month & $\mathbf{2 0 0 4}$ & $\mathbf{2 0 0 5}$ & $\mathbf{2 0 0 6}$ & $\mathbf{2 0 0 7}$ & $\mathbf{2 0 0 8}$ & $\mathbf{2 0 0 9}$ & $\mathbf{2 0 1 0}$ & $\mathbf{2 0 1 1}$ & $\mathbf{2 0 1 2}$ & $\mathbf{2 0 1 3}$ & $\mathbf{2 0 1 4}$ \\
\hline Jan & 31.18 & 48.01 & 20.57 & 18.40 & 22.26 & 21.12 & 11.29 & 10.09 & 7.02 & 4.67 & 6.12 \\
Feb & 57.15 & 41.10 & 492.18 & 79.20 & 35.80 & 90.63 & 15.30 & 18.65 & 18.35 & 27.58 & 21.08 \\
Mar & 7918.33 & 9620.82 & 14065.12 & 8412.98 & 10715.62 & 8832.26 & 9296.14 & 8323.65 & 7713.77 & 7559.41 & 5746.32 \\
Apr & 929.72 & 2864.35 & 1466.80 & 1484.33 & 898.26 & 1178.22 & 254.08 & 437.01 & 995.54 & 342.02 & 1452.15 \\
May & 90.30 & 357.72 & 80.48 & 84.38 & 310.59 & 103.76 & 40.33 & 70.38 & 106.06 & 100.51 & 207.74 \\
Jun & 290.20 & 51.71 & 71.56 & 98.02 & 296.12 & 48.60 & 30.26 & 195.58 & 21.98 & 46.20 & 52.10 \\
Jul & 693.98 & 1716.96 & 177.75 & 901.46 & 132.02 & 111.53 & 365.33 & 432.53 & 510.23 & 309.89 & 736.66 \\
Aug & 352.30 & 192.18 & 148.47 & 100.98 & 174.21 & 602.79 & 81.61 & 227.75 & 149.69 & 137.40 & 241.34 \\
Sep & 177.68 & 208.75 & 117.76 & 102.97 & 150.76 & 112.47 & 65.22 & 111.18 & 74.69 & 177.26 & 62.32 \\
Oct & 73.03 & 95.86 & 69.19 & 68.53 & 54.74 & 29.35 & 29.63 & 33.28 & 20.44 & 85.15 & 21.59 \\
Nov & 36.75 & 37.72 & 51.71 & 31.83 & 19.62 & 13.42 & 13.79 & 22.66 & 9.22 & 13.45 & 16.82 \\
Dec & 38.34 & 14.97 & 21.36 & 23.17 & 19.60 & 16.57 & 11.06 & 14.27 & 8.04 & 7.50 & 11.99 \\
\hline Sour & Paki & & & & & & &
\end{tabular}

Source: Pakistan Meteorological Department (2016)

This duration is very critical for allergy patients in the study area. In the year 2009 the peak pollen count for Broussonetia papyrifera was recorded in the month of March with a value of 4143.0 pollens $/ \mathrm{m} 2$ and the lowest was observed in month of September with a value of 1718.07 pollens $/ \mathrm{m} 2$. Same trend was observed in the year 2010 when peak pollen count was high in the month of March with a value of 4431.6 pollens $/ \mathrm{m} 2$ and the lowest was observed in the month of September. The sensitization profile of mulberryallergic patients and the proteins of paper mulberry pollen contributing to pollinosis in the Pakistani population (Micheal et al., 2013).

According to table 6, the average work-days loss due to pollen allergy is higher in the government servants as compared to common labors and students. But there is no significant variation in their monetary losses. From the statistics given in table 7 , it is clear that average health expenditures of a pollen patient is Rs. 879 per month in which the major cost they bear was medical cost. It is worth mentioning to note that the government employees are more effected from the pollen as compared to other labours because they are more exposed to open air and movement for their job due to which they lose their work days. These findings also match with the findings of Lamb et al (Lamb et al., 2006) and Crystal-Peters (Crystal-Peters, Crown, Goetzel, \& Schutt, 2000) who found that allergies is the major cause of absenteeism and presenteeism of working labours. In the sampled data, the average monthly health expenditures of the respondents from pollen allergy were amounted to Rs. 879 which is significant part of the poor families' income.

According to the experts consulted from Pakistan Agriculture Research Council (PARC), Department of Plant Science of Quaid-i-Azam University (QAU), Plant specialist and other 
JHRS, Vol. 2, 2020

Table 6: Loss of working days due to pollen allergy.

\begin{tabular}{ccc}
\hline Type of Effectees & Unit of Loss & Average Work Days Loss due to Pollen Allergy \\
\hline Labor & Rupees & 509.7 \\
Government servant & Rupees & 566.3 \\
Student & School days & 2.6 \\
\hline
\end{tabular}

Source: Field survey

Table 7: Monthly Average health expenditure due to pollen allergy.

\begin{tabular}{lcc}
\hline \multicolumn{1}{c}{ Cost } & Mean & Std. Deviation \\
\hline Total medical cost (Rs) & 565.31 & 253.51 \\
Laboratory cost (Rs) & 166.67 & 0.01 \\
Other Test or cost related to Medicine Cost (Rs) & 56.40 & 58.70 \\
Home treatment cost (Rs) & 43.61 & 83.90 \\
Adaptation strategies cost against allergy (Rs) & 1.18 & 3.30 \\
Other health cost (Rs) & 46.29 & 90.90 \\
\hline Total health cost (Rs) & 879.46 & 295.80 \\
\hline
\end{tabular}

Source: Field survey

experts, Pine Rexburg (Chear), Kachnar (Orchard) are the native plants of this area and have no negative effects on human health in comparison to paper mulberry. In other words, Pine Rexburg (Chear), Kachnar (Orchard) are more beneficial for human health as compared to paper mulberry. Furthermore, Kachnar tree is very useful for manufacturing of medicines and doesn't cause pollen count. Similarly, Pine tree doesn't have any health implications as compared to paper mulberry and it also doesn't contribute to pollen.

Kachnar tree has strong positive economic and environmental implications for human beings. The main positive effect is that it is very useful for manufacturing of medicines and its buds are used for the human livelihood while it does not have any influence in the pollen count in Islamabad.

Pine tree is a native plant. It does not have any negative effect on human beings. Its female plant has zero pollen effect which means that it does not have any negative effect on human health while male plant releases pollen during spring season but the pollen count is very low therefore has no significant effect on human beings.

The table 8 summaries the annual benefits of three trees. Storm water reduction is highest for the Pine Rexburg tree with the monetary value of 1100 PKRs annually. The storm water reduction is minimum for Paper Mulberry. The energy saving potential of Pine Rexburg and Kachnar are same but these are more than Paper Mulberry. The corban dioxide reduction of Pine Rexburg and Kachnar are also more than Paper Mulberry. The air quality improvement of Pine Rexburg is more as compared to Paper Mulberry. The total annul benefits (in monetary terms) of Paper Mulberry is less as compared to Kachnar and Pine Rexburg trees. This analysis further explores that from 
environmental viewpoint Pine Rexburg and Kachnar are the best alternatives for Paper Mulberry.

The detail of the annual cost of Paper Mulberry and its alternative plants are given in table 9. The cost include major heads such as initial purchase cost, pruning cost and removal cost. The total annual cost (in monetary terms) of Kachnar is less as compared to Paper Mulberry and Pine Rexburg trees. Pine Rexburg is most expensive as compared to Paper Mulberry and Kachnar.

Larger trees absorb more carbon from the atmosphere because of their larger biomass (McPherson, 2007; McPherson et al., 2002). The larger tree is also beneficial with respect to air quality improvement. While the similar valuation applies to precipitation reduction and storm water excess. Storm water reduction is highest for the Pine Rexburg tree as compared to Paper Mulberry.

The energy saving Pine Rexburg and

Table 8: Average Annual Benefits of Paper Mulberry and its Alternative

\begin{tabular}{|c|c|c|c|c|c|}
\hline $\begin{array}{c}\text { Plants/ } \\
\text { Variables }\end{array}$ & $\begin{array}{c}\text { Air quality } \\
\text { improvement } \\
\text { (PKRs.) }\end{array}$ & $\begin{array}{l}\text { Carbon dioxide } \\
\text { reduction } \\
\text { (PKRs.) }\end{array}$ & $\begin{array}{l}\text { Energy } \\
\text { Saving } \\
\text { (PKRs.) }\end{array}$ & $\begin{array}{l}\text { Storm Water } \\
\text { Reduction } \\
\text { (PKRs.) }\end{array}$ & $\begin{array}{l}\text { Total Benefit } \\
\text { (PKRs.) }\end{array}$ \\
\hline Pine Rexburg/Chear & 400 & 300 & 400 & 1100 & 2200 \\
\hline $\begin{array}{l}\text { Kachnar/ } \\
\text { Orchard Tree }\end{array}$ & 100 & 200 & 400 & 500 & 1200 \\
\hline Paper Mulberry & 200 & 50 & 200 & 300 & 750 \\
\hline
\end{tabular}

Source: National tree benefit calculator

Table 9: Average Annual Costs of Paper Mulberry and its Alternative

\begin{tabular}{lcccc}
\hline \multicolumn{1}{c}{\begin{tabular}{c}
\multicolumn{1}{c}{ Plants/ } \\
Variables
\end{tabular}} & $\begin{array}{c}\text { Initial Purchase Cost } \\
\text { (PKRs.) }\end{array}$ & $\begin{array}{c}\text { Pruning Cost } \\
\text { (PKRs.) }\end{array}$ & $\begin{array}{c}\text { Removal Cost } \\
\text { (PKRs.) }\end{array}$ & $\begin{array}{c}\text { Total } \\
\text { Cost } \\
\text { (PKRs.) }\end{array}$ \\
\hline Pine Rexburg/Chear & 450 & 100 & 200 & 750 \\
$\begin{array}{l}\text { Kachnar/ } \\
\text { Orchard Tree }\end{array}$ & 100 & 100 & 200 & 400 \\
Paper Mulberry & 00 & 300 & 400 & 700 \\
\hline
\end{tabular}

Source: Field Survey (2016)

Table 10: Annual Net Benefits of Paper Mulberry and its alternative trees

\begin{tabular}{lccc}
\hline $\begin{array}{c}\text { Net Benefit of } \\
\text { Plants }\end{array}$ & $\begin{array}{c}\text { Pine Rexburg (Chear) } \\
\text { tree } \\
\text { (PKRs.) }\end{array}$ & $\begin{array}{c}\text { Kachnar } \\
\text { (Orchard) Tree } \\
\text { (PKRs.) }\end{array}$ & $\begin{array}{c}\text { Paper Mulberry } \\
\text { (PKRs.) }\end{array}$ \\
\hline Total Benefit & 2200 & 1200 & 750 \\
Total Cost & 750 & 400 & 700 \\
Net Benefit & 1450 & 800 & 50 \\
\hline
\end{tabular}

Source: Author calculation based on the result derived from National benefit calculator. 
Kachnar are also more than Paper Mulberry. The corban dioxide reduction of Pine Rexburg and Kachnar are also more than Paper Mulberry. Similarly, air quality improvement of Pine Rexburg is more as compared to Paper Mulberry. At aggregate level, the annul benefits of Kachnar and Pine Rexburg trees are more than Paper Mulberry.

The total annual cost of Kachnar is less as compared to Paper Mulberry and Pine Rexburg trees. Pine Rexburg is most expensive as compared to Paper Mulberry and Kachnar. Besides, the annual net benefit of the paper mulberry are also less as compared to Kachnar and Rexburg trees. In nutshell, Pine Rexburg and Kachnar are viable alternatives for Paper Mulberry from both economic and environmental viewpoints.

According to table 10, Paper Mulberry has the minimum net benefit (Rs 50) as compared to Pine Rexburg tree (Rs 1450) and Kachnar (Rs 800). Further Pine Rexburg tree is more beneficial as compared to Paper Mulberry and Kachnar. The benefit cost ratio (Total annual benefits divided by total annual cost) of Pine Rexburg tree and Kachnar (Orchard) Tree are 2.94 and 3 respectively. The benefit cost ratio was favorably high in Kachnar and Pine Rexburg as against paper Mulberry (Table 11).

Table 11: Benefit Cost Ratio of Paper Mulberry and its Alternative plants

\begin{tabular}{cccc}
\hline $\begin{array}{c}\text { Plants/ } \\
\text { B/C Ratio }\end{array}$ & $\begin{array}{c}\text { Pine Rexburg } \\
\text { (Chear) tree } \\
\text { (PKRs.) }\end{array}$ & $\begin{array}{c}\text { Kachnar } \\
\text { (Orchard) Tree } \\
\text { (PKRs.) }\end{array}$ & $\begin{array}{c}\text { Paper Mulberry } \\
\text { (PKRs.) }\end{array}$ \\
\hline Benefit Cost Ratio & 2.94 & 3.00 & 1.08 \\
\hline
\end{tabular}

Source: Author calculation based on the result derived from National benefit calculator.

\section{Conclusion}

Based on the findings it is concluded that Pine Rexburg and Kachnar are the best alternative in terms of net benefits for Paper Mulberry in Islamabad. The Capital Development Authority should replace Pine Rexburg and Kachnar with Paper Mulberry in Islamabad. This will reduce the health costs of the effectees. Besides, Government should arrange awareness program especially in the pollen month which is March and should also provide free of cost treatment and preventives for the pollen patients.

\section{References}

Asthma and Allergy Foundation of America. (2017). Allergy Facts and Figures, http:// www.aafa.org/page/allergy-facts.aspx Accessed on January 26, 2017

Bennett, D. J., Qazilbash, M., \& Qazilbash, A. A. (1997). A Survey of Pollen Allergies in Six Villages of Islamabad: Sustainable Development Policy Institute.

Bosch-Cano, F., Bernard, N., Sudre, B., Gillet, F.,
Thibaudon, M., Richard, H., Ruffaldi, P. (2011). Human exposure to allergenic pollens: A comparison between urban and rural areas. Environmental research, 111(5), 619-625.

Crystal-Peters, J., Crown, W. H., Goetzel, R. Z., \& Schutt, D. C. (2000). The cost of productivity losses associated with allergic rhinitis. The American Journal of Managed Care, 6(3), 373-378.

D'amato, G., Spieksma, F. T. M., Liccardi, G., Jäger, S., Russo, M., Kontou $\square$ Fili, K., Bonini, S. (1998). Pollen $\square$ related allergy in Europe. Allergy, 53(6), 567-578.

D'amato, G., Cecchi, L., Bonini, S., Nunes, C., Annesi $\square$ Maesano, I., Behrendt, H., Van Cauwenberge, P. (2007). Allergenic pollen and pollen allergy in Europe. Allergy, 62(9), 976-990.

Ghufran, M. A., Hamid, N., Ali, A., \& Ali, S. M. (2013). Prevalence of allergenic pollen grains in the city of Islamabad, Pakistan and its impact on human health. Pakistan Journal of Botany, 45(4), 1387-1390.

Haroon, M. A., \& Rasul, G. (2008). Effect of 
meteorological parameters on pollen concentration in the atmosphere of Islamabad. Pakistan Journal of Meteorology, 4(8), 27-36.

Kandylis, K., Hadjigeorgiou, I., \& Harizanis, P. (2009). The nutritive value of mulberry leaves (Morus alba) as a feed supplement for sheep. Tropical animal health and production, 41(1), 17-24.

Lamb, C. E., Ratner, P. H., Johnson, C. E., Ambegaonkar, A. J., Joshi, A. V., Day, D., Eng, B. (2006). Economic impact of workplace productivity losses due to allergic rhinitis compared with select medical conditions in the United States from an employer perspective. Current medical research and opinion, 22(6), 1203-1210.

McPherson, E. G. (2007). Benefit-based tree valuation. Arboriculture and Urban Forestry, 33 (1), 1-11.

McPherson, E. G., Maco, S. E., Simpson, J. R., Peper, P. J., Xiao, Q., VanDerZanden, A. M., \& Bell, N. (2002). Western Washington and Oregon community tree guide: benefits, costs and strategic planting: International Society of Arboriculture, Pacific Northwest Chapter.

Micheal, S., Wangorsch, A., Wolfheimer, S., Foetisch, K., Minhas, K., Scheurer, S., \& Ahmed, A. (2013). Immunoglobulin E reactivity and allergenic potency of Morus papyrifera (paper mulberry) pollen. J Investig Allergol Clin Immunol, 23(3), 168-175.

Munoz, F., Delgado, J., Palma, J., Gimenez, M., Monteserin, F., \& Conde, J. (1995). Airborne contact urticaria due to mulberry (Morus alba) pollen. Contact Dermatitis, 32(1), 61-61.

National Institute of Health. (2014). The Allergy Centre Retrieved June 9, 2014, 2014, from http:// www.nih.org.pk/allergy_cntr.asp

Pakistan Meterological Department. (2012). Daily Pollen Count ( per m3 of air ) of Islamabad, from http://www.pmd.gov.pk/rnd/rndweb/rnd_new/R\% 20\&\%20D.php

Rashid, M., Abbas, S. H., \& Rehman, A. (2014). The status of highly alien invasive plants in Pakistan and their impact on the ecosystem: a review. Innovare Journal of Agricultural Sciences, 2(1), 1-4.

Seo, J.-H., \& Kim, H.-J. (2011). Component analysis of paper mulberry bark for the automation of bark peeling process. Journal of Korea Technical Association of The Pulp and Paper Industry, 43(1), 74-82.

Singh, B., \& Makkar, H. P. (2002). The potential of mulberry foliage as a feed supplement in India. Mulberry for Animal Production. SANCHEZ, MD (Ed.). Animal Production and Health Paper(147), 139-155.

White, J. F., \& Bernstein, D. I. (2003). Key pollen allergens in North America. Annals of Allergy, Asthma \& Immunology, 91(5), 425-435.

World Allergy Organization. (2011). World Allergy Organization White Book on Allergy, http://www.worldallergy.org/UserFiles/file/WAOWhite-Book-on-Allergy web.pdf accessed on January 26, 2016, from http:// www.worldallergy.org/UserFiles/file/WAO-WhiteBook-on-Allergy_web.pdf 